\title{
Metastatic breast cancer to colon: An unusual site of metastasis with a review of literature
}

\author{
Parham Nejati ${ }^{1}$, Masoud Sadeghi ${ }^{1,2}{ }^{\oplus}$, Farhad Amirian ${ }^{3}$, Mazaher Ramezani ${ }^{3, *}$
}

${ }^{1}$ Medical Biology Research Center, Kermanshah University of Medical Sciences, Kermanshah, Iran

${ }^{2}$ Students Research Committee, Kermanshah University of Medical Sciences, Kermanshah, Iran

${ }^{3}$ Molecular Pathology Research Center, Imam Reza Hospital, Kermanshah University of Medical Sciences,

Kermanshah, Iran

\section{Correspondence}

Mazaher Ramezani, Molecular Pathology Research Center, Imam Reza Hospital, Kermanshah University of Medical

Sciences, Kermanshah, Iran

Email: mazaher_ramezani@yahoo.com

\section{History}

- Received: Feb 08, 2019

- Accepted: Mar 19, 2019

- Published: Mar 31, 2019

DOI :

https://doi.org/10.15419/bmrat.v6i3.532

\section{Check for updates}

\section{Copyright}

(c) Biomedpress. This is an openaccess article distributed under the terms of the Creative Commons Attribution 4.0 International license.

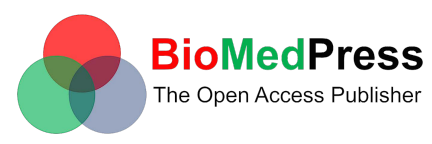

\begin{abstract}
Gastrointestinal (Gl) metastasis is very rare in patients with breast cancer (BC). This study reports a case with colon carcinoma metastasis originated from breast cancer in Western Iran. A 37-yearold female was diagnosed with infiltrating ductal carcinoma. Immunohistochemistry (IHC) results showed positive estrogen receptor, progesterone receptor, HER2 scored 2 out of 3, Ki-67 in $30 \%$ of tumor cells and P53. The patient was re-admitted two times with urinary and Gl symptoms, positive tumor markers and thick colon wall. Samples from the colon were collected to test for metastasis. The pathologist reported metastatic breast ductal carcinoma spread to the colon. The IHC showed CK7, CK20, GCDFP15, ER and PR positivity. In conclusion, this IHC panel can be considered as the differential and diagnostic markers for malignant GI lesion originated from breast cancer.

Key words: Case report, Colon, Infiltrating ductal carcinoma, Metastasis
\end{abstract}

\section{INTRODUCTION}

Breast cancer (BC) is the most frequent malignancy among women and is the second most common reason of cancer death in females globally ${ }^{1,2}$. One in eight women will be affected in their lifetime ${ }^{3}$. The most common cause of death in BC patients is distant metastasis ${ }^{4}$, and lungs, liver, bone, brain and adrenal glands are the most common sites of these metastases $^{1}$, whereas gastrointestinal (GI) tract metastasis, especially colorectal metastasis in these individuals are very rare and uncommon ${ }^{3,5}$. Therefore, clinicopathological findings are poor and unclear for the diagnosis and subsequent treatments of GI lesion, especially for colon carcinoma originated from BC. In this study, we report a very rare and uncommon case of BC that developed into colonic metastasis. In addition, we report the clinicopathological features distinguishing metastasis from primary malignancies by immunohistochemistry (IHC).

\section{CASE PRESENTATION}

A 37-year-old housewife was admitted to the surgery department with pain and insidious growth on left breast mass for 3 years on $14^{\text {th }}$ January 2013. On $15^{\text {th }}$ January, she underwent left breast modified radical mastectomy. The breast specimen was $14 \times 12 \times 6 \mathrm{~cm}$ in size with retracted nipple and infiltrating gray mass of up to $9.5 \mathrm{~cm}$ in the center of the breast. Several separated fibro fatty pieces of tissue about $8.5 \times 6 \times 2 \mathrm{~cm}$ were also present. The pathology report identified infiltrating ductal carcinoma with nuclear and histologic grade I/III, vascular and perineural invasion and free skin, nipple, and surgical margins. Three out of 8 axillary lymph nodes were involved by the tumor. IHC report on $14^{\text {th }}$ May 2013 was estrogen receptor (ER) positive (weak staining in $50 \%$ of tumor cells), progesterone receptor (PR) positive, the human epidermal growth factor receptor 2 (HER2) positive scored 2 out of 3 (weak complete staining in 100\% of tumor cells), Ki-67 positive in $30 \%$ of tumor cells, and $\mathrm{P} 53$ positive. The patient had a history of breast mass since 2010 with insidious growth and recent pain. Medication history in 2013 included Salbutamol Spray. The patient was admitted on $6^{\text {th }}$ December 2016 to the oncology ward with a history of 7 sessions of chemotherapy and 25 sessions of radiation therapy, with the last one in 2013, and clinical presentation of suprapubic pain, nausea, dysuria, and urinary retention for 7-8 hours. In physical examinations, suprapubic with right lower quadrant tenderness, a temperature of $38.3^{\circ} \mathrm{C}$ and blood pressure of $80 / 50 \mathrm{mmHg}$ were noted. The differential diagnoses included urinary tract infection, sepsis, metastasis, and appendicitis. Multiple ultrasound examinations during hospitalization demonstrated multiple Para-aortic, Para cava, Para iliac, mesenteric, and peritoneal lymphadenopathies sized $20-35 \mathrm{~mm}$ in favor of neoplastic process and tumoral peritoneal seeding. Left adnexal vascularized hypoechoic mass with the maximum diameter of $30 \mathrm{~mm}$, mass-like hypoechoic masses in right iliac fossa with the dimensions of 40x15 and 10x8 mm (metastatic lesions), and a round echogenic 


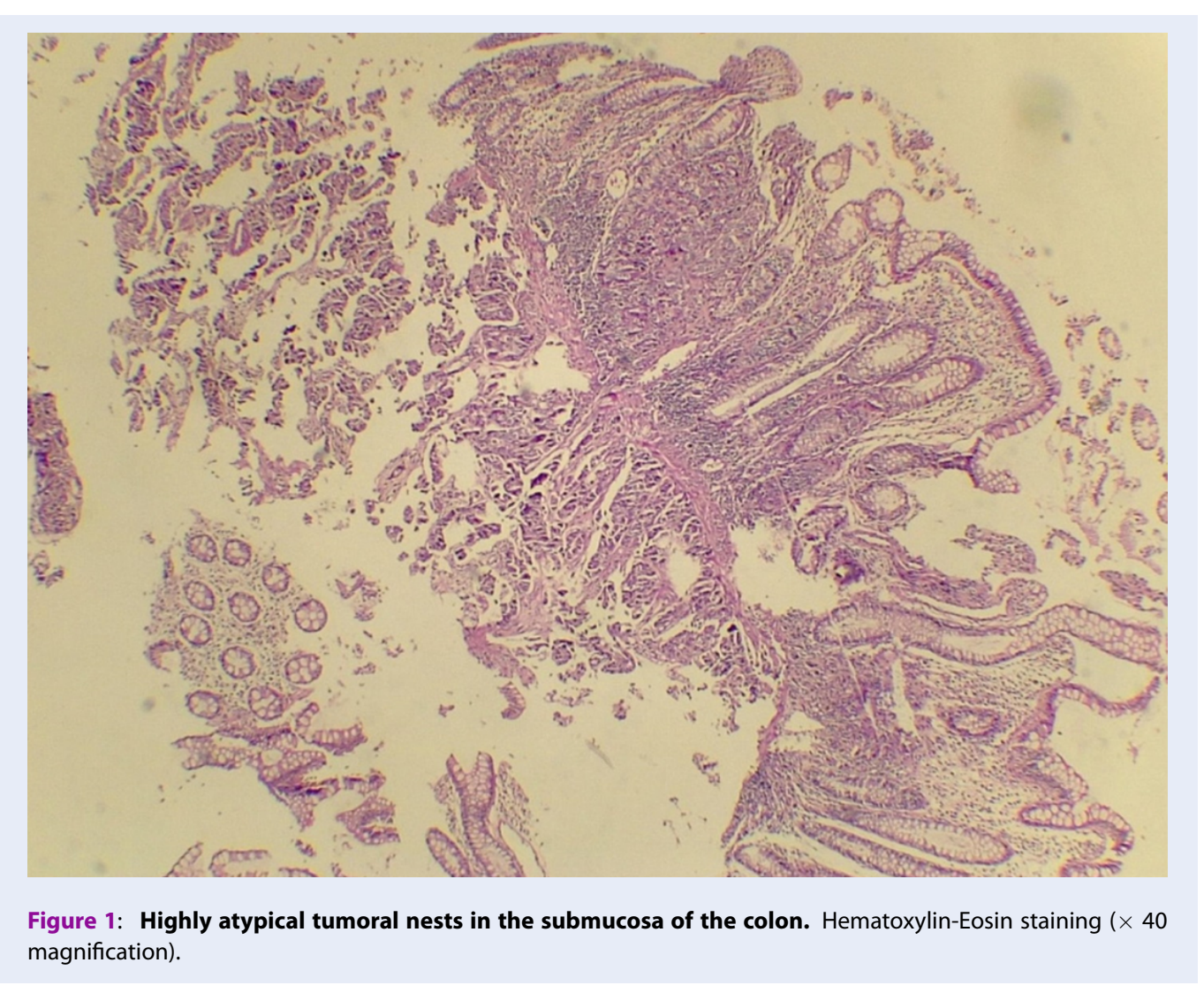

right ovarian lesion $\left(15^{\star} 11 \mathrm{~mm}\right)$ were also noted. The patient received treatment and was stable for discharge.

On $26^{\text {th }}$ January 2017, the patient was re-admitted to the oncology department with right inguinal inflammation and mass for a few weeks. Ultrasound examination showed multiple lymph nodes without echogenic hilum and maximum dimensions of $24 \times 16$ $\mathrm{mm}$ in favor of malignant lymph nodes. On $1^{\text {st }}$ February 2017 , the patient was admitted with abdominal pain and infection, positive tumor markers and thick colon wall, and samples from the colon were collected to test for metastasis. The specimen consisted of several fragments of creamy brownish tissue about $0.9 \times 0.7 \times 0.3 \mathrm{~cm}$ in size with colonoscopy biopsy. The pathologist reported colon mucosa overlying malignant epithelial tumor compatible with clinical diagnosis of metastatic breast ductal carcinoma in the colon (Figures 1, 2 and 3), and suggested IHC for confirmation. IHC was done on $7^{\text {th }}$ February and showed positive CK7, CK20, GCDFP15, ER, and PR, which confirmed metastatic carcinoma of breast origin.

On $28^{\text {th }}$ March 2017, the patient was re-admitted with chief complaint of flank pain, oliguria and anuria for 2-3 days. Physical examination was unremarkable, except for costovertebral angle tenderness and lower limbs edema. Abdominopelvic computed tomography (CT) scanning showed bilateral hydronephrosis, which was a candidate for left nephrostomy. Doppler ultrasound suggested deep venous thrombosis in both lower limbs. On $7^{\text {th }}$ April 2017, patient was faced with loss of consciousness and chorea-like movements, but brain CT scanning was unremarkable. Magnetic resonance imaging was not possible due to patient general condition. On $11^{\text {th }}$ April the patient was intubated due to tachycardia and tachypnea. Clinical diagnosis included sepsis, acute renal failure, and septic shock in advanced cancer. On $12^{\text {th }}$ April 2017, cardiopulmonary arrest was faced. Cardiopulmonary resuscitation (CPR) was done, but the patient died $40 \mathrm{~min}$ utes after CPR.

\section{DISCUSSION}

GI metastasis originated from BC is very rare, therefore, it is rarely recognized ${ }^{5}$. Distant metastasis may occur many years after BC therapy ${ }^{6}$. However, some studies suggested that ductal carcinoma have the tendency to metastasize to liver, lung, and brain, and lobular BCs are significantly associated with bone, GI tract, gynecological organs ${ }^{7}$. We found a 37-year-old 


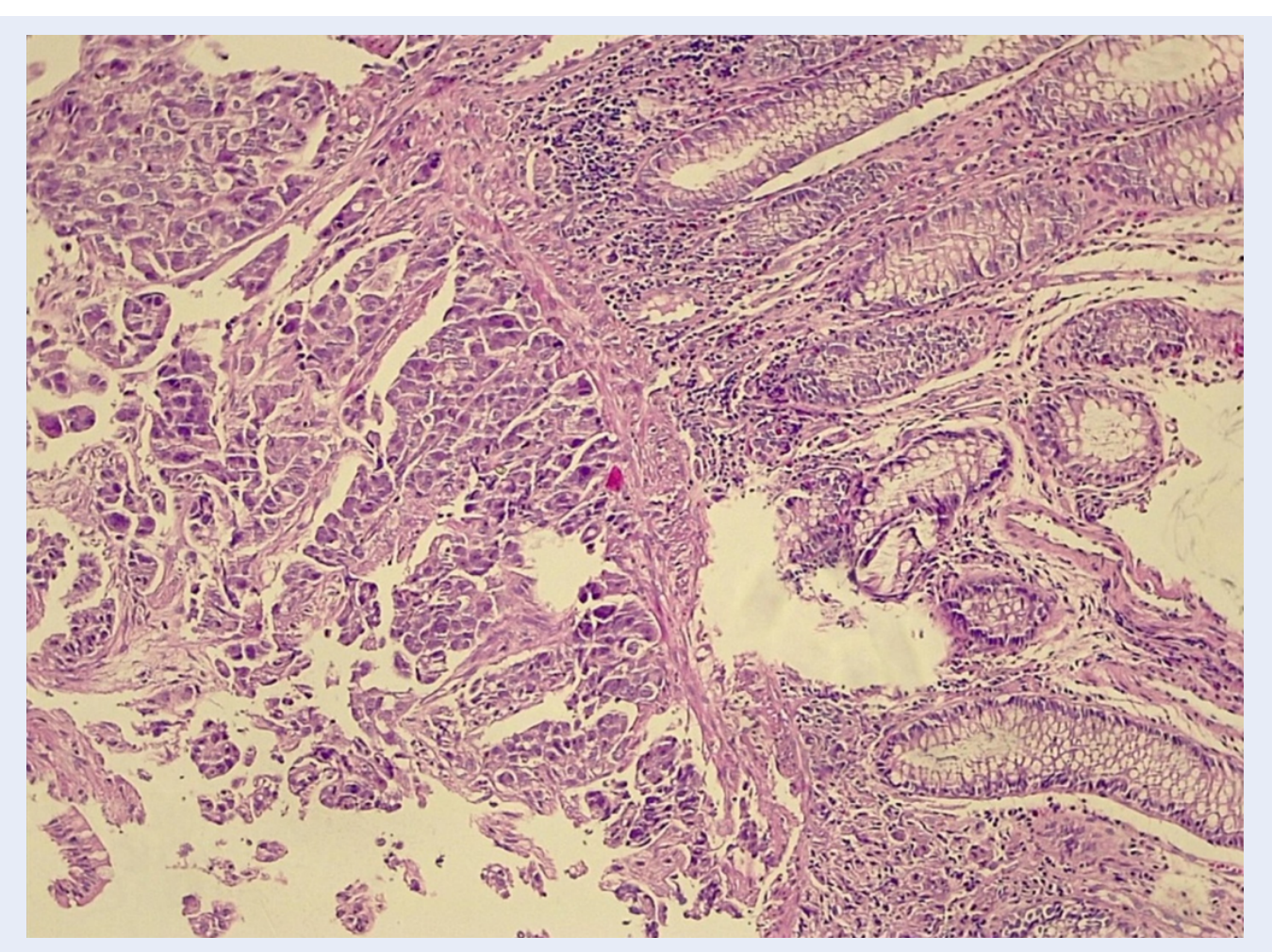

Figure 2: Metastatic tumoral nests in the submucosa of the colon, infiltrating pleomorphic malignant cells. Hematoxylin-Eosin staining ( $\times 100$ magnification).

patient with metastatic infiltrating ductal carcinoma in colon. Due to the late-onset and clinical symptoms of colon metastasis, the screening was difficult. Thus, immunohistochemistry analysis played a significant role in accurate and differential diagnosis. Our IHC results showed that the biopsy specimens were positive for CK20 and CK7. Since CK7 was significantly expressed in $90 \%$ of $\mathrm{BC}$ carcinomas, we could identify the malignant lesion in CK7 positive specimens as metastatic BC, which was compatible with previous studies. On the other hand, previous studies have shown that CK20 staining is particularly positive in gastrointestinal tract tumors ${ }^{8}$, Additional immunohistochemical examinations showed positivity for ER and PR, like that seen in primary BC. These findings recommended that malignant colonic lesion might be metastatic from BC, however, $32 \%$ and $12 \%$ of gastric cancer biopsied samples were ER and PR positive ${ }^{9}$. In this regard, Pera et al. ${ }^{10}$ showed positivity for ER and PR in more than $90 \%$ of the malignant gastric cells. In another study, Koike et at. ${ }^{11}$ reported 3 positive cases for ER and PR staining, which indicated GI metastasis from BC.

As sensitivity and specificity of GCDFP-15 staining for determining breast origin of cancers are about
$55-76 \%$ and $95-100 \%$ respectively, and it has been used for differential diagnosis of metastatic $\mathrm{BC}^{3,6,7}$. GCDFP-15 staining of the present case showed positivity, which was in agreement with the other studies $^{6,9}$.

\section{CONCLUSIONS}

Colon metastasis from $\mathrm{BC}$ is very rare. Considering the importance of correct diagnosis in order to choose the optimal initial treatment, histopathological and immunohistochemical analysis gives researchers new insight into determining the histological origin of carcinomas. The present case reported the positivity for CK7, CK20, GCDFP-15, PR, and ER in immunohistochemical analyses that were well matched to that of breast lesion observed. However, there is no specific markers available to determine the malignant metastatic GI tract lesion from the primary one. Based on our results and previous studies, the combination of CK7, CK20, GCDFP-15, PR, ER can be employed as useful markers for the diagnosis of colon metastasis from BC.

\section{ABBREVIATIONS}

BC: Breast cancer 


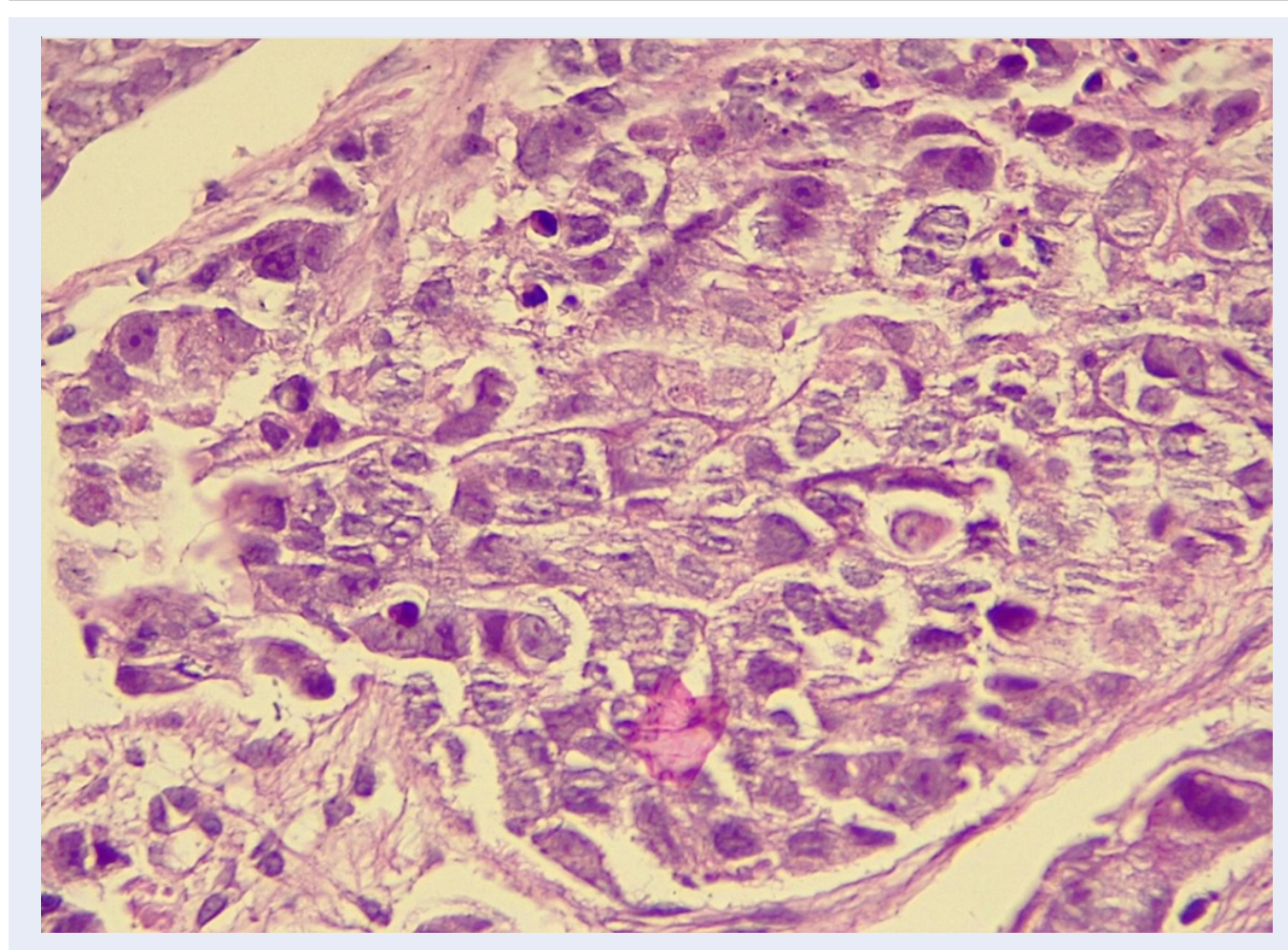

Figure 3: Nests of a metastatic tumor, pleomorphic large nuclei. Hematoxylin-Eosin staining $(\times 400$ magnification).

CPR: Cardiopulmonary resuscitation

CT: Computed tomography

ER: Estrogen receptor

GI: Gastrointestinal

HER2: Human epidermal growth factor receptor 2

IHC: Immunohistochemistry

PR: Progesterone receptor

\section{COMPETING INTERESTS}

There are no conflicts of interest.

\section{AUTHORS' CONTRIBUTIONS}

Parham Nejati \& Mazaher Ramezani: Literature search, Clinical studies, Data acquisition, Data analysis; Mazaher Ramezani: Manuscript preparation, Manuscript review, Guarantor; Parham Nejati: Concepts, Design, Definition of intellectual content, Literature search, Manuscript editing; Masoud Sadeghi \& Farhad Amirian: Manuscript editing, Literature search. All authors read and approved the final manuscript.

\section{REFERENCES}

1. Guzmán JCV, Espinosa J, Cervera R, Delgado M, Patón R, García JMC. Gastric and colon metastasis from breast cancer: case report, review of the literature, and possible underlying mecha- nisms. Breast Cancer (Dove Med Press). 2016;9:1-7. 28096693. Available from: 10.2147/BCTT.S79506.

2. Martin R, Mathews W, Scarcliff S. A rare presentation of breast cancer: near obstructing rectal mass and gastric outlet obstruction. J Surg Case Rep. 2016;2016(9):rjw162. 27672104. Available from: 10.1093/jscr/rjw162.

3. Schwarz RE, Klimstra DS, Turnbull AD. Metastatic breast cancer masquerading as gastrointestinal primary. Am J Gastroenterol. 1998;93(1):111-4. 9448188. Available from: 10.1111/j. 1572-0241.1998.111_c.x.

4. Uygun K, Kocak Z, Altaner S, Cicin I, Tokatli F, Uzal C. Colonic metastasis from carcinoma of the breast that mimics a primary intestinal cancer. Yonsei Med J. 2006;47(4):578-82. 16941751. Available from: $10.3349 / y m j .2006 .47 .4 .578$.

5. Taal BG, den Hartog Jager FC, Steinmetz R, Peterse $H$. The spectrum of gastrointestinal metastases of breast carcinoma: II. The colon and rectum. Gastrointest Endosc. 1992;38(2):136-41. 1568609. Available from: 10.1016/S00165107(92)70378-2.

6. Pectasides D, Psyrri A, Pliarchopoulou K, Floros T, Papaxoinis G, Skondra $\mathrm{M}$, et al. Gastric metastases originating from breast cancer: report of 8 cases and review of the literature. Anticancer Res. 2009;29(11):4759-63. 20032432.

7. Harris M, Howell A, Chrissohou M, Swindell RI, Hudson M, Sellwood RA. A comparison of the metastatic pattern of infiltrating lobular carcinoma and infiltrating duct carcinoma of the breast. Br J Cancer. 1984;50(1):23-30. 6331484. Available from: 10.1038/bjc.1984.135.

8. Tot T. The role of cytokeratins 20 and 7 and estrogen receptor analysis in separation of metastatic lobular carcinoma of the breast and metastatic signet ring cell carcinoma of the gastrointestinal tract. APMIS. 2000;108(6):467-72. 11028811. Available from: 10.1111/j.1699-0463.2000.tb01158.x. 
9. Jones GE, Strauss DC, Forshaw MJ, Deere H, Mahedeva U, Mason RC. Breast cancer metastasis to the stomach may mimic primary gastric cancer: report of two cases and review of literature. World J Surg Oncol. 2007;5(1):75. 17620117. Available from: 10.1186/1477-7819-5-75.

10. Pera M, Riera E, Lopez R, Viñolas N, Romagosa C, Miquel R. Metastatic carcinoma of the breast resembling early gastric carcinoma. Mayo Clin Proc. 2001;76(2):205-7. 11213310. Available from: 10.1016/S0025-6196(11)63129-7.

11. Koike K, Kitahara K, Higaki M, Urata M, Yamazaki F, Noshiro $\mathrm{H}$. Clinicopathological features of gastric metastasis from breast cancer in three cases. Breast Cancer. 2014;21(5):62934. 21779814. Available from: 10.1007/s12282-011-0284-3.

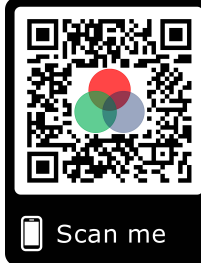

